\title{
The Roma people in Bulgaria - Their number and localization, from the Liberation (1878) until the beginning of the $21^{\text {st }}$ Century
}

\author{
Nadezhda Borissova Ilieva \\ Bulgarian Academy of Sciences \\ National Institute of Geophysics, Geodesy and Geography \\ Akad G. Bonchev 3, Sofia, 1113, Bulgaria \\ nadeto.ilieva@abv.bg
}

\begin{abstract}
The main objective of this study is to trace accurately the changes in the number and in the location of the Roma ethnic group, which has constituted no more than $2 \%$ of the population during the whole history of Bulgaria after The Liberation (1878). In this study, general and regional features of the dynamics of demographic processes and spatial distribution of the Roma in Bulgaria have been followed through and some main trends in the development of these processes have been established.
\end{abstract}

Keywords: number of Roma population, demographic development, spatial mobility and spatial location of Roma ethnic group.

\section{Introduction}

In recent years not only in Bulgaria but also in Europe, and around the world, an increased interest in problems related to the ethnic communities is observed, in particular in their number, demographic development, spatial mobility and spatial location. In Bulgaria, this interest is mostly directed to the Roma ethnic group.

There is strong discrepancy between the number of the Roma reported in the official census results and the number estimated through scientific and empirical research. Consequently, wild speculations on this topic spread in the society and in the media and further complicate the relations between ethnic communities in the country. All that imposes a necessity of exploring this topic on the basis of a scientific study in an attempt to establish the actual number and location of the Roma ethnic group in Bulgaria.

The current situation in the number and location of the Roma ethnic group is a result of its demographic development throughout different periods. The study covers the years from The Liberation of Bulgaria (1878) till the beginning of the XXI century. Such a retrospective analysis makes it easier to clarify the current status of the Roma ethnic group. Despite the prolonged co-existence of Bulgarians and Roma too little is known about the Roma in Bulgaria. So far, no complex geographical 
study of this population has been made, which includes the same time span and covers the entire present territory of Bulgaria.

The information necessary for realization of the current study, is provided by the following main sources:

- Statistics on the ethnic composition of the population, in particular of the Roma ethnic group - census data for the period from The Liberation till the beginning of the $21^{\text {st }}$ century;

- Roma-related data accessible in the archive funds after the year 1989 - Central State Archive - Sofia

- Other information from scientific and other studies on the Roma ethnos in Bulgaria.

While reviewing the data sources it can be concluded that despite some shortcomings in the period 1900-2011 a rich set of statistical data exists and allows to correlate ethnic structures throughout the entire period, regardless of the different methodological approaches used in the censuses, and enabling us to analyse the processes of change in these structures on a strict scientific basis.

Correct assessment of the different stages, which the formation and the development of the different ethnic groups in Bulgaria has passed through, is the first step in conducting a modern state policy toward those groups, which will also contribute to a natural and full integration, in particular of the Roma, with the Bulgarian nation as a distinctive ethnic community, with equal rights, with its own specific ethno-cultural group characteristics.

\section{Methodological approach}

Clarification of the conceptual-terminological apparatus is one of the important methodological problems related to the study of ethnic groups. For the purposes of the current study, the main attention is devoted to the concepts of "ethnic group" and "national minority", as well as to the particularities in the formation, development and the characteristic signs of the Roma ethnic group.

The term „ethnic group” denotes part of a given ethnicity, which exists in the territory of another state, surrounded by other ethnicities or lives dispersed among them featuring a lot of specific elements of the culture, language, unitary ethnic consciousness of the individuals. The people who form ethnic groups are usually bilingual and even multilingual. An ethnic group should be studied historically because of the dynamics of its development.

As of today, there is no definition for „national minority” adopted in the international and Bulgarian legislation. However, that term is used in various international documents, such as the Framework Convention for the Protection of National Minorities of the Council of Europe. In Bulgaria the constitutional court came with a decision that the term is conventional, i.e. not a legal term, hence lacking a clear legal definition and scope of application.

In the current study major signs of ethnicity (such as culture, language, religion, common origin, common territory, ethnic consciousness, etc.) are taken into consideration and analysed, refracted through the specific nature of the Roma ethnicity. None of the features should be absolutized for there is no exact rule of defining an ethnic group. Therefore, the implementation of an integrated approach towards exploring problems of this kind seems most logical. This implies that when characterizing an ethnos, its features should be regarded as a complex. It should be noted that each of the ethnic features taken into consideration in the study is not specific to just one ethnicity only. Furthermore, the nature of each ethnos is formed not by some single component but is composed of a 
combination of inherent objective characteristics. That does not mean that the ethnos is represented by some mechanical assembly of features; it is a whole entity where certain components play the role of system-creating elements. In some cases, such role is played by the language, in others - by cultural characteristics, etc. In the investigated Roma ethnicity, a leading, unifying element is the nature of behaviour, culture, the common historical destiny, the attitude of surrounding society toward Roma groups. These elements played the role of a strong consolidating factor, regardless of the lack of some of the basic features of the ethnic communities. Ethnic features are not permanent and mandatory for all historical periods in the development of a given ethnos. Many examples of ethnic communities which have lost its territorial, economic and partly linguistic integrity exist, and yet - they have preserved their self-dependant way of life (the Roma are typical example in this regard).

Many researchers highlight a certain type of a pre-class society ethnic community, which type strongly resembles the modern Gypsy ethnos. Gening (1970) suggests that these "supra-tribe” ethnic communities should be called "intergroups" (intergroup ethnic community). Several authors assign Roma ethnic community to "intergroups” for the following reasons: the Gypsy community is not a homogeneous community and is divided into a number of internal subgroups, each one bearing the attributes of the ethnic group (Maruschiakova 1992); Roma groups are often hostile to each other; many of them have their own potestary (group) authorities; various dialects differ to such extent that the members of the various groups are not able to understand each other; anthropological features and macrosociety attitude toward them has helped to create the awareness of a community and solidarity, and the common land of origin, along with the similar historical fate of the groups, despite the huge differences between them, are the reasons for the emergence of common cultural and historical features (Maruschiakova 1991); complex hierarchical structure of the ethnic consciousness (Popov 1991) etc.

Although ethnic communities are generally characterized by stability, they undergo some changes in time, preserving some continuity. To explain in detail the reasons for the changes in the ethnic structure it is necessary to consider the nature and symptoms of the ethnic processes. Ethnic processes are classified as ethno-generating, ethno-evolutionary and ethno-transforming and further on - the nature of those processes, their way of manifestation and specific characteristics are also clarified. The main role in the development of the ethnic processes among the Roma is being played by the group organism which has stabilizing effect and retains individual groups in their current stage of development.

Several classification schemes of the Roma ethnos in Bulgaria exist in which classifications usually a single leading attribute of the ethnic community is taken into account, such as the ethnic consciousness in some of the cases (Maruschiakova 1992; Tomova 1995; Kertikov; 2002), while in other cases, that leading attribute is the common dialect (Pamporov 2006, 2008). Maruschiakova (1992) combines more indicators of different kinds in an attempt to elaborate an ideal hypothetical model of the Gypsy group. She further compares different categories of Roma groups with the model and thus determines the degree of degradation of their ethnic identity. The proposed scheme by Marushiakova is built on the specific features of the Roma self-consciousness and their contemporary state. Other additional criteria are the language, the way of life, boundaries, endogamy, professional specialization, the time when they settled in Bulgarian lands, etc. Marushiakova offers a widely built hierarchical classification of the Roma population and its groups in Bulgaria, and marks three groups of Roma: settled gypsies (the so-called Yerlyi); former nomads (the so-called Kardaraschi or Vlach gypsies), and Roma gypsies (i.e. Romanian-speaking gypsies). Tomova (1995) offers another 
classification based on empirical sociological research. That classification is based on the comparison between data for self-declared belonging and expert evaluation. Later, in 2002, Kertikov (2002) determines the Roma in accordance with the direction of their self-declared belonging: Bulgarianized, Turkicized and Gypsy Roma. Pamporov $(2006,2008)$ offers his classification of the Roma in Bulgaria by marking the dialect community to which the Roma groups belong. Two communities are highlighted: Balkan community - strongly influenced by the Greek, Turkish and Bulgarian language and Vlashka (Vlach) community - influenced by the Romanian dialects. Pamporov divides the first community into two groups: Dasikane (Bulgarian) Roma and Horohane (Turkish) Roma. To the Vlashka dialect community, Pamporov $(2006,2008)$ defines three groups: Kaldarashi, Kalaydzhii and Rudari/Ludari.

This brief survey can be summed up in a conclusion that it is very difficult to make a commonly accepted classification of the Roma ethnicity, because of the specific characteristics of the Roma as an ethnic community on one hand, and because of the dynamic nature of the changes, which occur in the Roma ethnos as a whole, as well as in the various Roma groups, on the other.

(a)

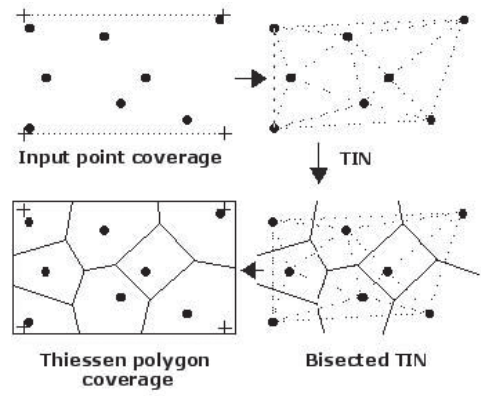

(b)

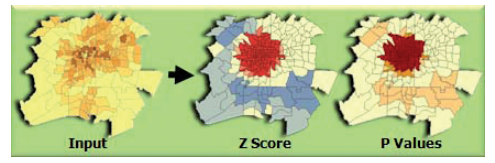

(c)
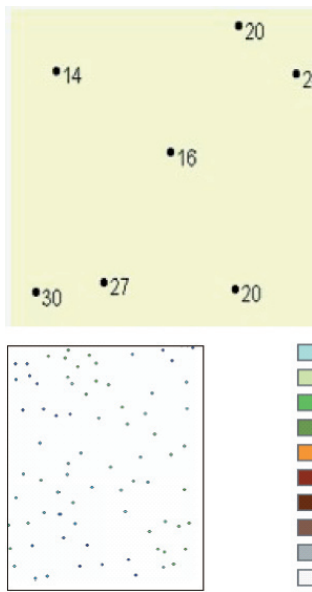

24

\begin{tabular}{|l|l|l|l|l|}
\hline 13 & 14 & 16 & 20 & 23 \\
\hline 14 & 14 & 16 & 19 & 24 \\
\hline 18 & 16 & 16 & 18 & 22 \\
\hline 24 & 22 & 19 & 19 & 21 \\
\hline 30 & 27 & 23 & 20 & 20 \\
\hline
\end{tabular}

Low

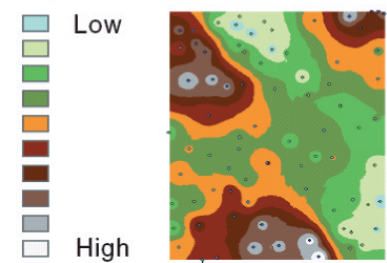

Figure 1. Examples of "Voronoy polygon" (a) and the application of the "Hot Spot Analysis” (b) and "Inverse distance Weighted (IDW)" function (c)

Source: http://www.supermap.com/EN/online/Deskpro\%2525206.0/SDTechTheme/.

To achieve the study purpose and in accordance with the assigned tasks the following general and specific methods of scientific research are used, being considered as the most appropriate: analysis and synthesis, comparative geographical analysis for the detection of similarities and differences in the territorial distribution of the number and location of the Roma population, mathematical-statistical mapping with the use of GIS for spatial analysis and visualization, analysis of literature sources, etc. Several mathematical methods associated with mathematical modelling as well as various tools in ArcGIS were used in defining regions with compact Roma population (over $10 \%$ of the total population, which is 3 times higher than the national average): the coefficient of ethno-territorial community, the compactness coefficient, conditional density of the ethnic group in the studied area, conditional area of settling of the ethnic group, the actual density of the ethnos; actual area of settling of the ethnic group (or total ethnic area - consisting of areas with predominant population from the studied ethnic group), mosaic coefficient, the method of geometric proximity (Ilieva 2009), 
which in its nature allows the generation of "Voronoy polygons" - part of the geo-spatial analysis in ArcGIS (Fig. 1a), as well as the ArcGIS tools: „Inverse Distance Weighted” (Fig. 1b) and „Hot Spot Analysis” (HSA) (Fig. 1c).

\section{Factors affecting the number and location of Roma ethnicity in Bulgaria}

Analysis of the factors affecting the number and the location of the Roma ethnic group during three different historic periods has been done in the study. The analysis of the first period (from Bulgarian Liberation till the end of the Second World War) shows that this was the first stage of demographic transition of the Bulgarian Roma, which was characterized by high birth rates (about $40 \%$ ), high mortality rates (about $20 \%$ ) and moderate natural growth of the population (about $20 \%$ ).

The Bulgarian government policy towards the ethnic groups, in particular towards the Roma ethnic group, was hesitant - it started with reduction of the rights of the Bulgarian Roma after The Liberation (1878), followed by decades of revocation of the existing political and cultural restrictions. This process was interrupted by the government led by Al. Stamboliyski (1919-1923) and also during the years of the Second World War in relation with the worsening situation of the ethnic groups in the country. Regardless of the government policy the Roma people seemed to have found favourable conditions for life in Bulgaria, which was demonstrated by the directions of migration and by the positive migration balance. All these processes promoted growth of the Roma ethnic group throughout that first part of the discussed period.

The second period in consideration coincides with the years of the so-called socialist development of the country (since the end of the Second World War (WWII) till the end of 1989) and could be characterized as a period of deepening differences in the demographic indicators between the Roma ethnic group and the other ethnic communities in the country. In each ethnic community the different stages of demographic transition are characterized by different intensity, duration and features, depending on the specific influence of the historical, socio-economic and ethno-cultural features. From the detailed analysis of the natural and the migration movement of the Roma ethnic group in Bulgaria, between WW II and the end of the eighties of the previous century, the following conclusions can be formulated:

- The first phase of the demographic transition of the Roma ethnic group, which was featured by moderate natural growth (up to $20 \%$ ) as a result of high birth rates (around and over $40 \%$ ) and high mortality rates (20\%) (Fig. 2), continued till the beginning of the fifties of the previous century. These years coincide with the first phase of demographic transition of the Turkish ethnic group, whereas for the Bulgarian population this phase ceased with the end of First World War. 


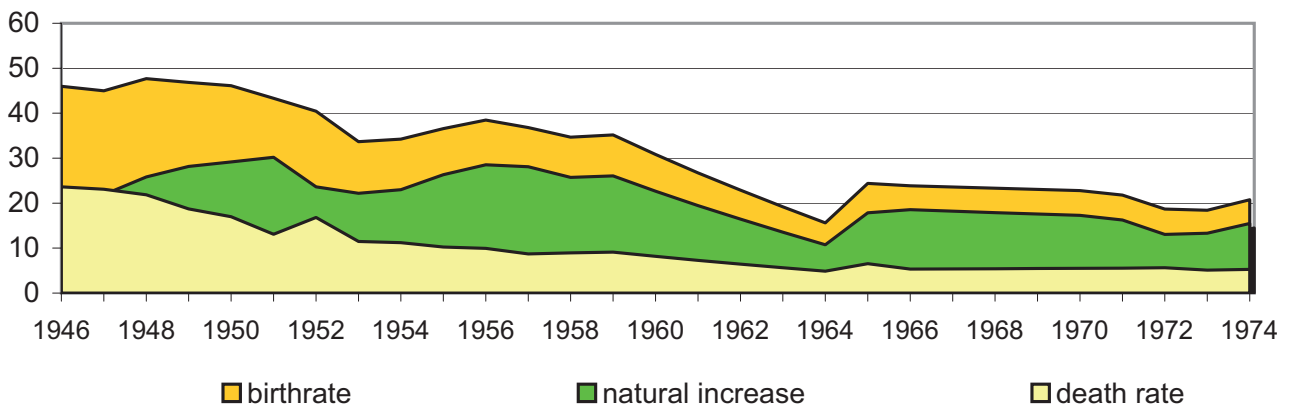

Figure 2. Birth rates (\%), death rates (\%) and natural increase (\%) of Roma population in Bulgaria (1946-1974) ${ }^{1}$

- The second phase of the demographic transition of the Roma population was featured by a quick increase of the natural growth as a result of the rapid reduction of the mortality rate combined with the relatively slow decrease in the birth rate (Fig. 2). By contrast, the Bulgarian population was featured in that phase by a quick decrease of both - mortality and birth rates, hence, no such sharp increase of the natural growth was observed. The second phase of the demographic transition of the ethnic Bulgarians ended by the beginning of the fifties of the previous century - the time when it had only just began for the Roma and the ethnic Turks in Bulgaria. High values of natural growth of Roma population were typical till the end of the nineties of the previous century, while for the Turks - they were only typical till the end of the seventies of the previous century- by the time when the second phase of the demographic transition of the ethnic Turks in Bulgaria ended.

- The third phase of the demographic transition of the Bulgarians was characterized by a continuous decline of the birth rate, combined with increasing of the mortality rate, which resulted eventually in changing the values of the natural growth from zero to negative. This was a sign of going into the fourth phase of the demographic transition, which occurred in the beginning of the eighties of the previous century. For the Bulgarian Turks the third phase had just began at that time, and a specific feature of that phase was the lack of rapid increase of mortality rate, due to the retained younger age structure of that population group.

The policy towards ethnic groups in the country was characterized again by too much inconsistency regarding their status. In the beginning of that period the Bulgarian authorities established a number of rights of the ethnic groups in the country and thus contributed to their cultural and economic progress. Bulgarian authorities also gave them freedom of ethnic and religious self-declaring. In the sixties and early seventies of the previous century, the Bulgarian state began to revaluate its previous policy by starting gradual restrictions of the rights of the ethnic minority groups and by pursuing progressive deletion of ethnic differences. Up till then, a presumption existed according to which the ethnic groups in the country would unite into a single nation by equalizing the economic, political, social, spiritual and psychological indicators of the various ethnic communities. Since the beginning of the eighties of the previous century, a new idea was launched - the idea of homogenization of the Bulgarian nation, by carefully organized „revival process” starting namely

\footnotetext{
1 Natural reproduction data by ethnicity were only gathered till 1974
} 
with the Bulgarian Roma. A decision was taken that the growing trend of Roma Muslims of Turkish mother tongue declaring themselves as Turks should be stopped by changing the Turkish-Arabic names to Bulgarian names, which policy began to be applied to Roma people at the end of the sixties of the previous century. As a result, however, the opposite effect was achieved -the number of Roma declaring themselves as Turks or Bulgarians began to grow. Up till then, emigration abroad was restricted, thus contributing to an increase in the Roma population in the country. A certain part of the Muslim Roma were involved in the so-called "Big excursion” (politically triggered emigration of Turks and other Muslims to Turkey), but an accurate assessment of the number of the Roma who left the country is impossible.

The third period started after 10th November 1989. Despite the political changes in Bulgaria, the problems of the Roma population were not resolved completely. The adopted Constitution in 1991, in which the most important legal foundations were embedded, provides full civil and political rights for all citizens, regardless of their ethnic consciousness. In the years following 1989, a number of measures aimed at overcoming discrimination and respecting the rights of the ethnic groups in the country, were taken:

- Synchronization of the domestic legislation with the European standards in the field of human rights and protection of minorities;

- Political, socio-economic and cultural integration of minorities into Bulgarian society;

- developing of an adequate institutional mechanism, which covers all levels of different types of authorities, with clearly defined responsibilities and powers;

- Consistent and effective implementation of the Framework Convention For Protection Of National Minorities (Council of Europe 2003).

The development of the state after 1989 poses new issues of the situation of the Roma ethnic group in the country, which need to be solved.

The decline of living standards in the country, deterioration of the living conditions and unequal status of the ethnic groups on the labour market along with the ethnic discrimination of the unemployed as well as the unfavourable educational structure of the Roma additionally aggravate the differences between ethnic communities in the country and destroy the stereotypes of behaviour and their relationships, exacerbating the ethnic tensions.

Over the past two decades, and especially after 1989, birth rates among all ethnic communities decreased as a result of severe economic crisis and the sense of insecurity caused by the social changes in the country. Nevertheless, the decrease of birth rates of the Roma is the smallest. Natural growth of the Roma in the period 1990-2000 was estimated at about 19\%; birth rate - $27 \%$ ond mortality rates $8 \%$. Since the beginning of the XXI century the natural increase fell by three to four points per thousand. The level of education, the material and cultural needs, the satisfaction of certain aspirations for education and child raising, as well as children value assessment, determine high birth rates and high natural growth of the Roma.

Two periods in the Bulgarian Roma emigration process after 1989 can be clearly outlined: a period of weak emigration mobility till the beginning of the $21^{\text {st }}$ century; and a second period (the first decade of the 21st century) - of increased emigration as a result of joining the so-called Schengen “White List” by Bulgaria (April 2001) and the EU accession (January 2007), which along with the socio-economic problems that accompany the transition period prove to be crucial for the Bulgarian Roma in making a decision to emigrate. Between $1^{\text {st } J a n u a r y ~} 2002$ and $1^{\text {st }}$ January 2007 their share grew to $3.0 \%$, but the largest increase was observed after the EU accession of Bulgaria (1 January 2007) - 9.9\% (Angelov \& Vankova 2011). 


\section{Dynamics of the number of Roma in Bulgaria}

The analysis of the factors for population number concludes that the natural growth has been the main factor of the growth of Roma population in Bulgaria. The ethno-cultural characteristics, the specifics of employment, the impact of the standards imposed in the value system of the Roma group, combined with the specificity of the settlement environment, the young age structure, the deteriorating educational structure and the livelihoods, are the key factors that largely determine the maintenance of high levels of natural growth of the Roma population. Decisive influence on the birth rate decrease, and respectively on the natural growth, had the final settling down of the Roma regulated by Decree № 258 of the Council of Ministers from 17 $7^{\text {th }}$ October 1958 which coincided with the completion of the land collectivization and with a raise of the educational level of the Roma. The next significant drop in the values of the reproduction indicators was observed in the middle of the first decade of the 21st century when accelerated rates of transition to the third phase of demographic transition were sensed.

Throughout the whole period after The Liberation, immigration prevails over emigration which generally has low intensity, and hence little influence on the number of Roma in country, with only few exceptions (for example during the so-called "Big excursion” and the years after 2001).

During the entire period following The Liberation, the Roma is the only ethnic group in the country which was showing a continuous increase in number (with the exception of the 1920 census when the results were affected by changes in the territory of Bulgaria, the 1975 census - when the results were classified and the ones that were published were not the actual results, and with the exception of the 2011 census - according to official statistics the number of the Roma group has decreased since the previous census, but in fact its increasing continues) (Fig. 3).

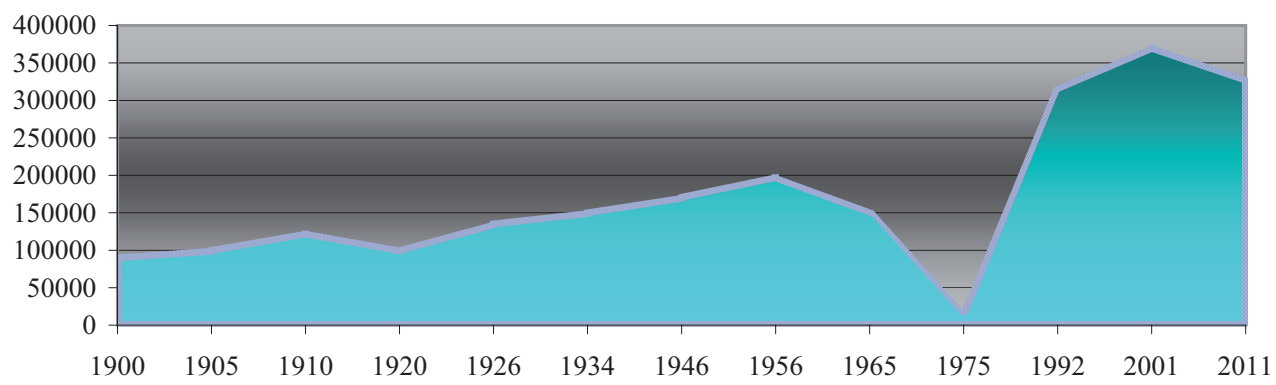

Figure 3. Number of the Roma in Bulgaria (1900-2011)

Throughout the first period (between The Liberation and the end of WWII) the Roma population number grew by $90 \%$. During the second part of the discussed period - between the end of WW II and 1989, the number of Roma nearly doubled (growth of 92\%). During the third part of the discussed period (after 1989), two subperiods stand out - from the beginning of the nineties till the end of the 20th century, which period was featured by fast growth of the Roma population in the country due to the limited Roma emigration; and a second subperiod - overlapping the first decade of the 21st century - when a decrease of the Roma population was detected, modelled by an increasing emigration as a result of poor economic conditions and increased social insecurity in the country. The actual number of Roma population is about 600 thousand people. Tomova (1995) estimates, based on 
comparison between self-identification data and expert assessment, that only $2 / 3$ of the Roma tend to identify themselves as such. The lower number reported in censuses is due to the phenomenon of dual ethnic identity - a part of the Roma identify themselves as Bulgarians and others as Turks. The first reason is that it occurs in some Roma who largely lost its previous group characteristics (the weaker the group is, the lesser the array of typical features of a Roma group and the stronger the peripheral self-consciousness is). The second reason is the attitude of mainstream society and its institutions against Roma (Maruschiakova 1992).

\section{Territorial location features of the Roma}

Unlike the Turkish ethnic group, the Roma people live dispersed among the general population and, therefore, no typical areas of high Roma settling density have been formed in the country.

Each particular Roma group is economically connected to an ethnically different environment, while the contacts between the various Roma groups often are totally lacking. Therefore, the integration process within the Roma ethnic community as a whole is weak (Marushiakova \& Popov 1993). One of the reasons why Roma live across the whole territory of a given country, not just in Bulgaria, is the specific character of their professions and crafting which they practice to make a living, but yet cannot support a large group of Roma. This forces them to split into relatively small units and to maintain closer economic relations with other ethnicities rather than with their own. It is those relations that contribute to the formation and transformation of the Roma ethnic self-consciousness, and make the estimation of the exact number of Roma difficult.

Despite the widespread opinion of the public that the Roma expand in territorial aspect, the number of settlements with Roma population has risen insignificantly - from 1857 right after The Unification of Bulgaria in 1885 to 2069 by 1992, and that number is almost unchanged till the last census of 2011. The significant increase of the relative share of Roma in those settlements, however, is another issue.

Throughout the whole period between The Liberation (1878) and 2011 - the year of the last census - two areas stand out as areas of highest concentration of Roma population - North-eastern and South Central Bulgaria, where half of the Roma population in Bulgaria is concentrated. The lowest concentration of Roma is measured in South-western, North Central and South-eastern Bulgaria, where the share of Roma does not exceed $15 \%$ of the total population. North-western Bulgaria occupies an intermediate position in that aspect (Fig. 4). Similar to the trends in the development of Roma-inhabited settlements, the development of Roma concentration can also be divided into two periods - till the beginning of the nineties, and the years to follow. Up till the beginning of the nineties, no significant changes in the Roma concentration occurred, with the exception of the lowering concentration of Roma in North-eastern Bulgaria after 1910 as a result of incorporation of territories after the Balkan Wars (1912-1913), and thus achieving more uniform distribution of the Roma in Bulgaria. Since the beginning of the nineties, a trend of growing concentration of Roma in South-western Bulgaria has been detected, (mostly due to the growing number of Roma in the capital city of Sofia), as well as in South Central Bulgaria and South-eastern Bulgaria, while in the three Northern regions of the country - a decrease of the Roma population number has been measured. That decrease is most significant in North-western Bulgaria, which is in total unison with the depopulation processes typical for that part of the country (Fig. 4). 
(a)

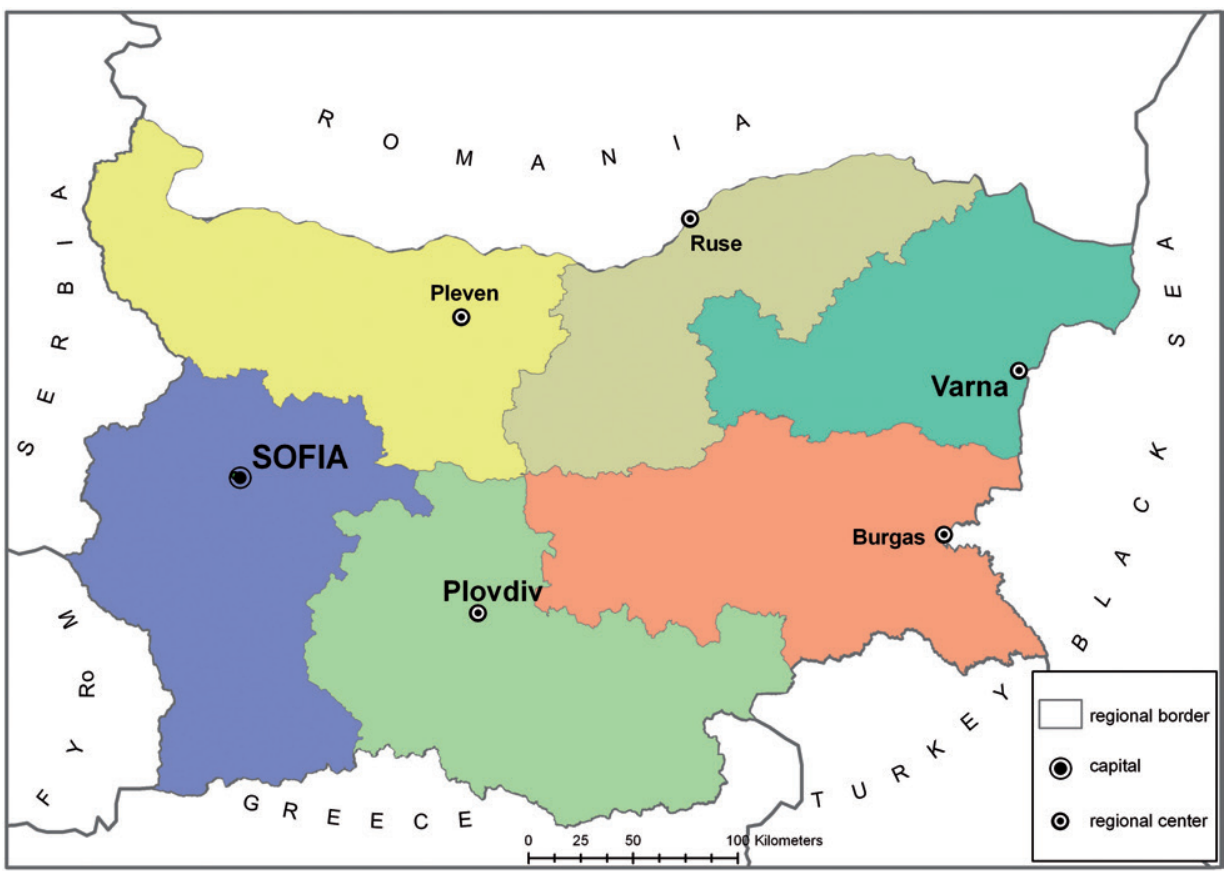

(b)

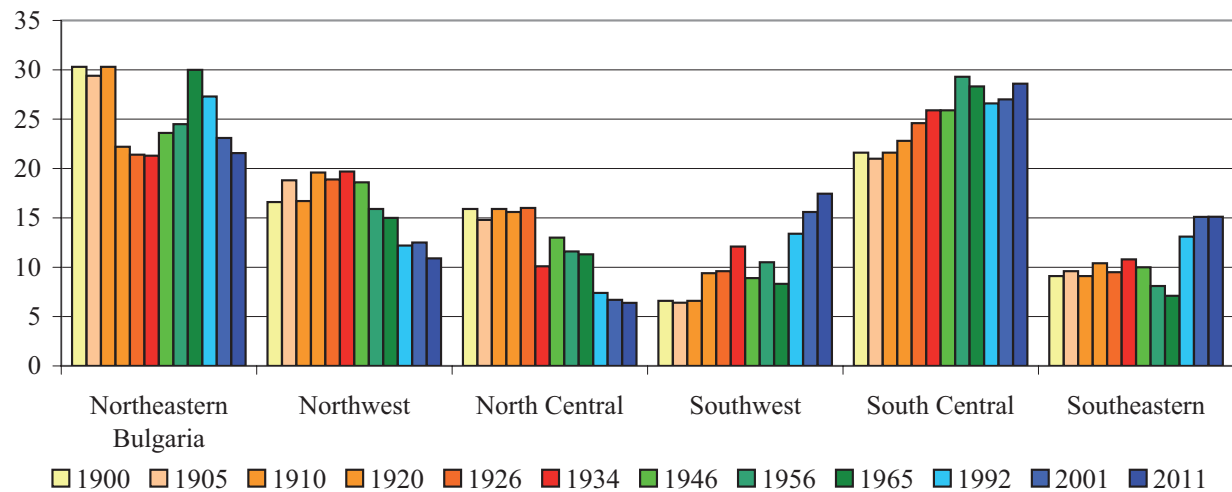

Figure 4. a) Bulgarian regions; b) Concentration of Roma population (\%) in different parts of the country for the period 1887-2011

Up till the beginning of the nineties, no major deviations from the national average share of the Roma population were observed in the different parts of the country. The relative share of Roma is higher than the national average value in North-western, North-eastern and in some occasions (censuses) - in South-eastern Bulgaria. During the whole period in focus, South-western and North Central Bulgaria stand out with the lowest share of Roma with values lower than the national average. Since the beginning of the nineties, along with the growth of relative share, an increase in differences in the various parts of the country is also visible, especially in recent years. The most significant growth of the relative share of Roma is being observed in North-western Bulgaria, where despite the decrease of concentration of Roma population, an increase of the 
relative share of Roma is also occurring due to the extreme depopulation processes among the ethnic Bulgarian population in that part of the country. A significant growth of the relative share of Roma is also visible in South-eastern, South Central and North-eastern Bulgaria. North Central and South-western Bulgaria stand out with their lowest relative share of Roma with the smallest changes in its values (Fig. 5).

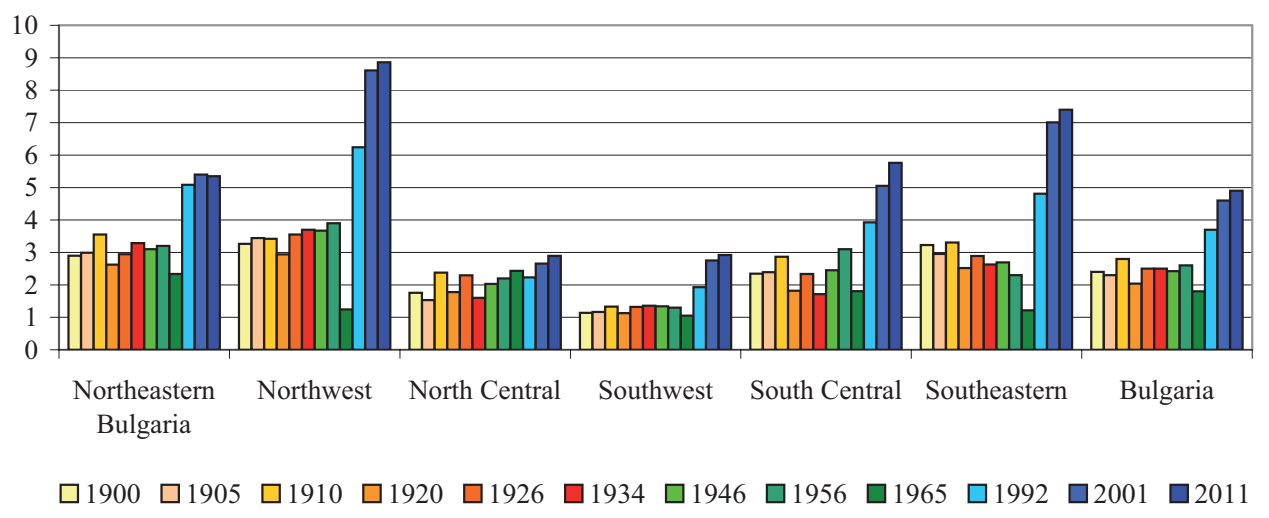

Figure 5. Relative share of the Roma population in the different parts of the country (1900-2011)

If the relative share of Roma is scrutinized on a lower territorial level (municipalities), significant differences can be found. Throughout the whole discussed period the municipalities in Western and Eastern Rodopi Mountains, the Kraishte region, Central Stara Planina and the adjacent area of the Predbalkan region, Central Danube plain and South-western Bulgaria stand out for the lowest relative share of Roma population. Generally, till the beginning of the nineties only a few areas of higher relative share of Roma had shaped out, while in all other parts of the country the relative share of Roma was close to the national average. Till the beginning of WW II those were the municipalities of North-western Bulgaria (in particular - the Western Danube plain), Pazardzhik region, Sliven region, Eastern Stara Planina and the adjacent Predbalkan region, as well as some municipalities in the Ludogorie region (Fig. 6a, Fig. 6b). Since the end of WW II till the beginning of the 1990s (Fig. 6b, Fig. 6c), an increase of the relative share of Roma had been observed in all municipalities. That increase was most significant in the above mentioned municipalities (with the highest share of Roma), as well as in some municipalities which since the end of the $20^{\text {th }}$ century stand out for significantly higher relative share of Roma (up to twice the national average). Those municipalities are located in Southern Dobrudzha region, the Central Sub-Balkan valleys, Stara Zagora region, Haskovo region, some municipalities along the Southern Black Sea coast. The area of increased share of Roma has expanded significantly in the Plovdiv-Pazardhik region, Western Stara Planina region and in some municipalities in South-western Bulgaria such as Kyustendil, Tran, Samokov and Ihtiman (Fig. 6c). Till the end of the discussed period (that is the 2011 census), growth of the relative share of Roma has been observed (Fig. 6d) in all parts of the country. The trend of increasing of Roma population number in the above mentioned territories continues. The highest relative share of Roma (over 15\% of the total population) and the highest growth in number of municipalities with such a relative share (from 10 in 1992 to 40 by 2011) has been detected in the South Dobrudzha region (Kaynardzha, Dobrich, Nikola Kozlevo and Kavarna), in North-western Bulgaria (Belogradchik, Chuprene, Ruzhintsi, Lom, Valchedram, Yakimovo, 
Brusartsi, Medkovets, Berkovitsa, Varshets), in the Central Sub-Balkan valleys region (Tvarditsa, Maglizh, Gurkovo, Nikolaevo), in the Eastern Stara Planina and Predbalkan region (Varbitsa, Kotel, Antonovo), in some municipalities in Strandzha-Sakar region (Straldzha, Sredets), in the area of Pravets, Yablanitsa and Lukovit, and in some other municipalities in various parts of the country, such as Tran, Lybimets, Simeonovgrad, Brezovo, Vetovo, Borovo, Provadia, Perushtitsa, Krichim, Rakitovo, Lesichovo and Ihtiman.

(a)

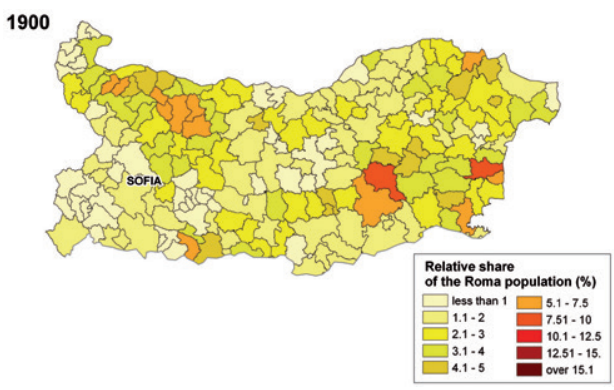

(c)

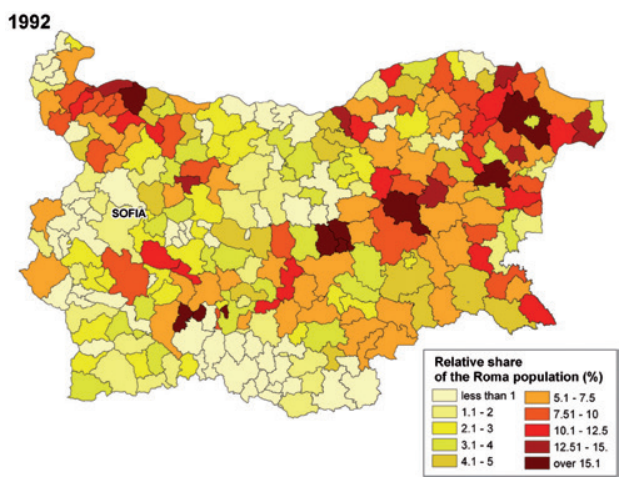

(b)

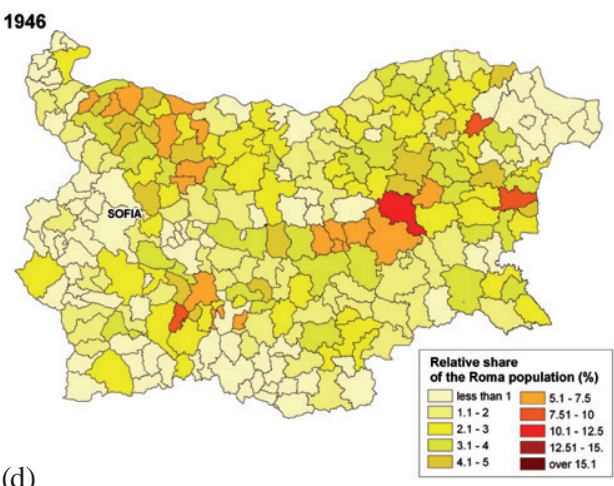

(d)

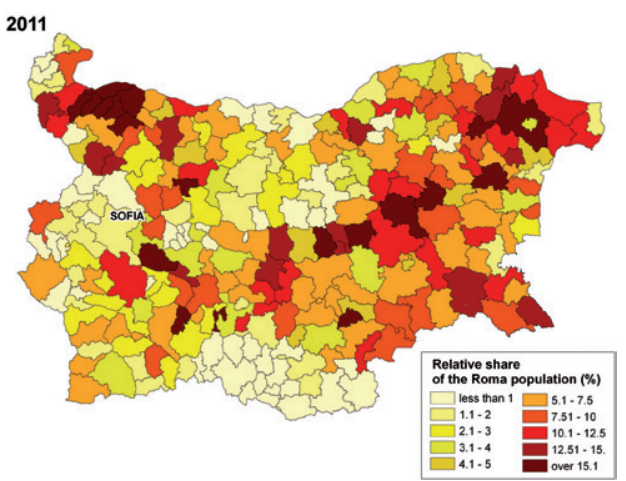

Figure 6. Relative share of the Roma population in 1900 (a), 1946 (b), 1992 (c), 2011 (d)

Until the beginning of the fifties the share of Roma living in urban settlements was higher than the shares of the Bulgarian and the Turkish urban population (fig. 7). Since the end of WW II a clear trend of growing concentration of Roma in urban settlements has been observed as a result of the higher migration rate of the Roma on the one hand and because of granting urban status to many settlements with a large number of Roma on the other. By the end of the discussed period nearly half of the Roma population in the country resides in urban settlements, which makes the Roma ethnic group less urbanized than the Bulgarian, but more urbanized than the Turkish ethnic group, exceeding its urban population by 10 percentage points. In recent years, intensification of migration towards urban settlements is being observed - Roma move to the cities in search of a way out of the heavy economic crisis and the rising unemployment. The concentration of Roma is quite visible in the large cities - nearly half of the urban Roma population resides in urban settlements with population of over 10 thousand people. 


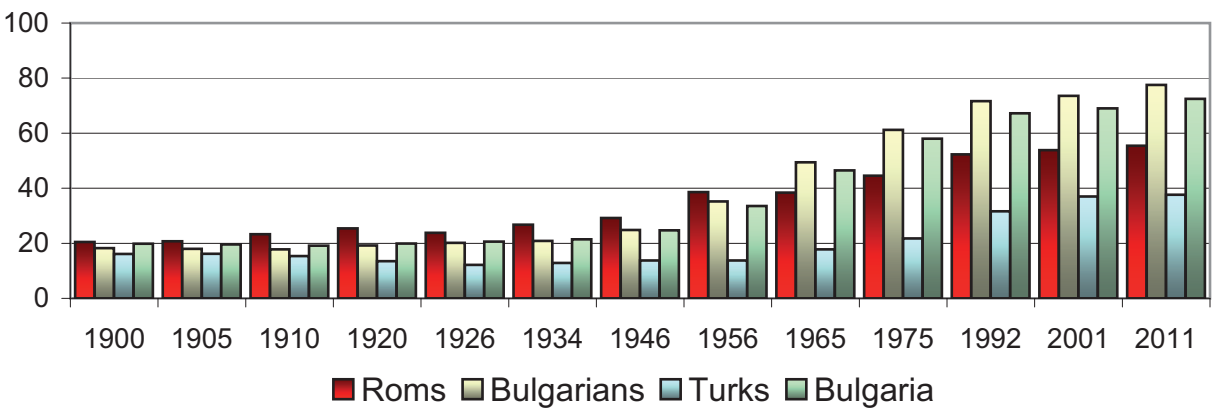

Figure 7. Relative share of the population of the main ethnic communities in urban settlements (1900-2011)

As far as the structure of the settlements according to the share of Roma is concerned, two periods can be outlined:

- Till the beginning of the nineties - a period when the settlements with low relative share of Roma (less than $10 \%$ of the total population) represent a significant share (over $85 \%$ ) of the settlements with presence of Roma, where as much as $65 \%$ of all Roma people resided. (Fig. 8 a,b); Those settlements are distributed evenly across the territory.

(a) $100 \%$

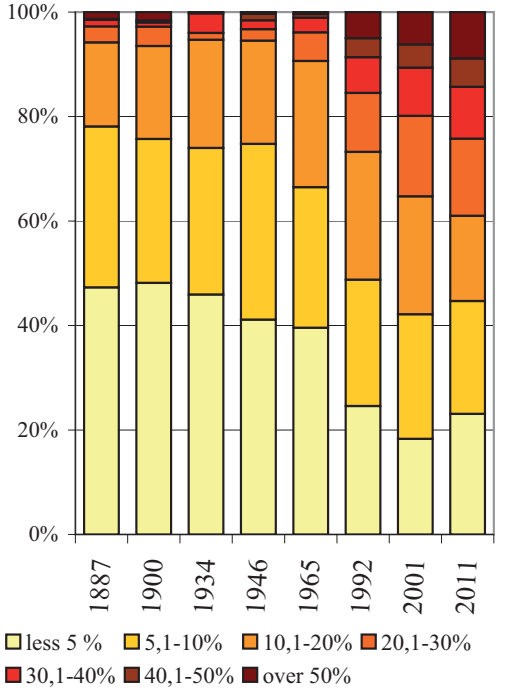

(b)

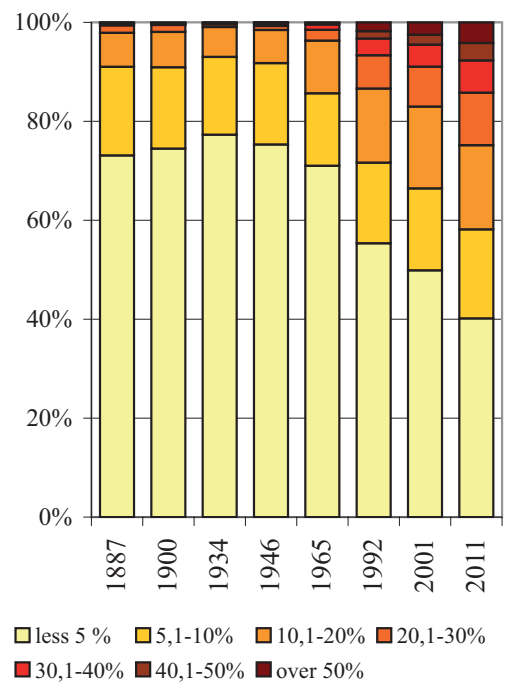

Figure 8. Distribution of the Roma ethnic group in the settlements with different relative share of Roma in Bulgaria (1887-2011) (a); distribution of settlements with different relative share of Roma population in Bulgaria (1887-2011) (b)

- Till the beginning of the nineties, the settlements with relatively significant share of Roma (10-30 \% of the total population) were mostly concentrated in North-eastern Bulgaria and in particular - the Ludogorie region, Eastern Stara Planina and the Predbalkan region, where some $70 \%$ of all settlements of that group (share of Roma 10-30 \%) were located. Other areas of distribution of settlements of the same group (till 1989) are the Pazardhik-Plovdiv Field and the Eastern Sub-Balkan valleys region. Since the beginning of the nineties, the number 
of settlements in that category has been growing, as well as their territorial distribution - in North-western Bulgaria, the Central Sub-Balkan valleys and the Maritza River valley eastwards of Plovdiv (Fig. 9).

(a)

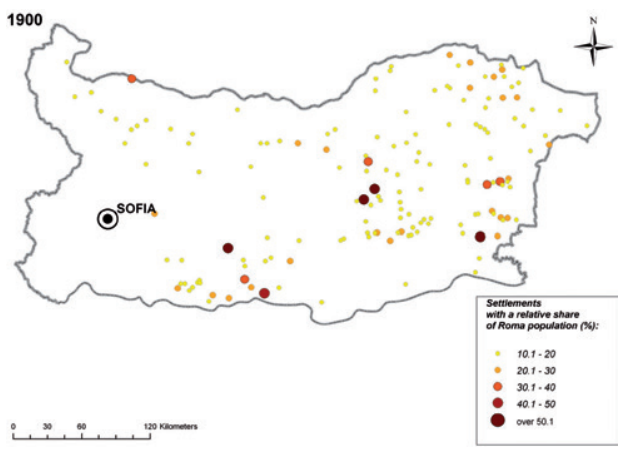

(c)

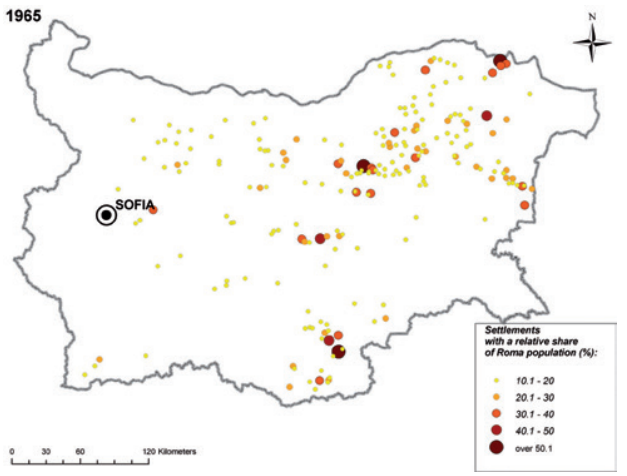

(e)

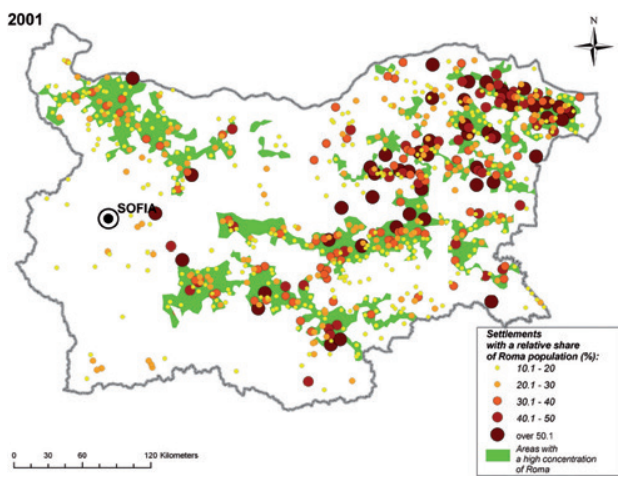

(b)

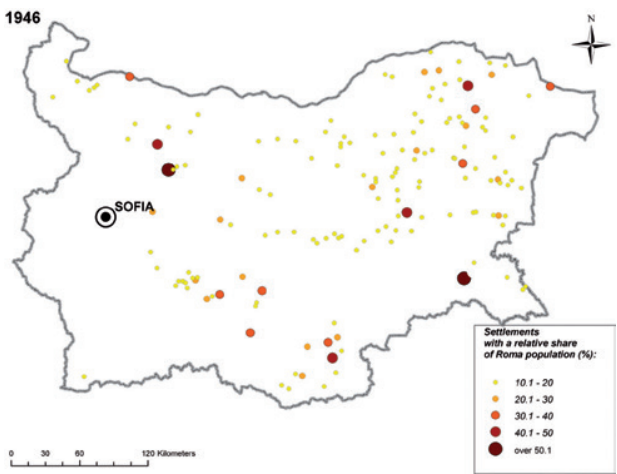

(d)

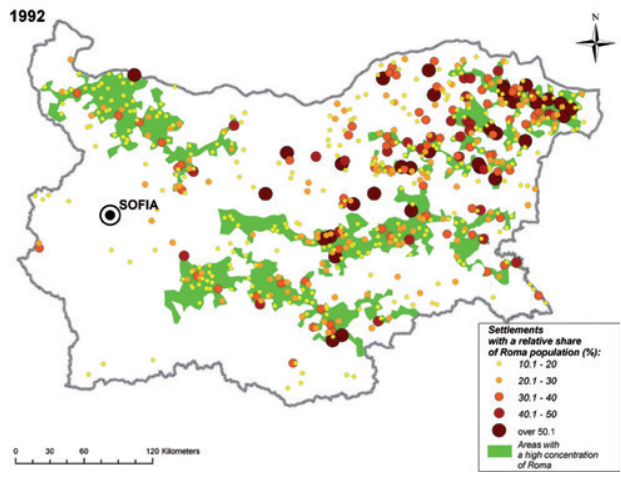

(f)

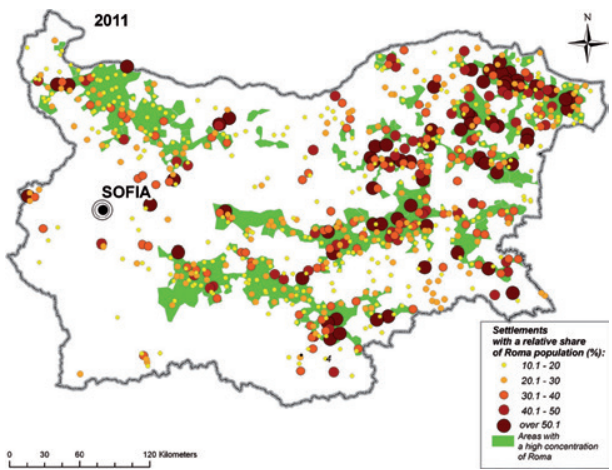

Figure 9. Roma ethnic group in Bulgaria by settlements and areas with a high concentration of Roma in 1900 (a), 1946 (b), 1965 (c), 1992 (d), 2001 (e), 2011 (f) 
- For a long period of time (until the beginning of the nineties) the settlements with very high relative share of Roma (over 30\% of the total population) constituted an insignificant share of the total number of settlements with Roma presence, and concentrated less than $5 \%$ of the total number of Roma in the country (fig. 8). Since the beginning of the nineties, however, the share of such settlements in the structure of Roma populated settlements grew up to $18 \%$ by 2011. Till the beginning of the nineties, $80 \%$ of those settlements were located in Northeastern Bulgaria (mainly in South Dobrudzha region). Since then, the territorial distribution of those settlements has been expanding in the Eastern Sub-Balkan valleys region, Haskovo region, Stara Zagora region and Burgas region (Fig, 9).

- The majority of the Roma population in the country is concentrated in settlements, where they form up to $10 \%$ of the total population. However, similar to the changes occurring in the structure of Roma populated settlements, the share of Roma living in that group of settlements (share of Roma up to $10 \%$ ) has been decreasing for the last two decades, and by the end of the discussed period less than half of the Roma in the country live in that type of settlements. According to the last three censuses, a gradual increase of the number of Roma living in settlements with very high share of Roma (30-40\%, 40-50 \% and over $50 \%$ of the total population), has been observed (Fig. 8.).

\section{Formation and development of areas with a high concentration of Roma}

The nineties emerged as the beginning of the formation of areas with high concentration of Roma population (AHCRP). Until then according to various censuses separate "islands" with a greater concentration of Roma could be outlined, which occupied small area and did not form a compact territory. Those small areas were changing their location and had no permanent character.

The main factors for the emergence of areas with a high concentration of Roma population are as follows:

- An increase in the total number and the relative share of the Roma population.

- High levels of population growth, which, despite the trend of reductions remain high at the beginning of the XXI century, estimated at around $18 \%$.

- The change in the ethnic structure of the settlements and the significant increase of settlements with high share of Roma population;

- Growing spatial dislocation of Roma settlements, especially those with high share of Roma;

- Reduction of the Turkish ethnic group, particularly in areas of compact settlement of Bulgarian Turks, as a result of emigration;

- High rates of decrease of the Bulgarian population in the villages as a result of deteriorated age structure and the ongoing migration to cities.

- In the future, taking into account the specific features of the demographic processes of Roma, the Bulgarians, the Turkish ethnic group and the smaller ethnic groups, the upward trend in the covering larger geographical area and the changes in the structures of those ethnic groups will continue (Fig. 9).

In 1992, four areas with a high concentration of Roma population formed, which were named according to their geographic location - North-western, North-eastern, Marishki and Balkan area, 
covering some $11.7 \%$ of the area of the country. In 2001 another area near Burgas has emerged, which occupies less than $1 \%$ of the national territory. Other areas with high concentration of Roma population mark territorial expansion in 2001 and they reach 16.1\% of the Bulgarian territory. Up to the last census (2011), this increase continued at a slower pace, so that those areas occupied $20.2 \%$ of the state territory.

In the above-mentioned areas more than half of Roma people in Bulgaria are concentrated, and according to the last three censuses these values have gradually risen as follows: in $1992-56.1 \%$, $2001-76.6 \%$, and in 2011 - 83\%).

\section{Conclusion}

The Roma-related problems have many aspects and their solution is complicated. The situation in Bulgaria is complicated by the fact that it ranks among the countries with the highest total number and also share of Roma population on the one hand, and the aggravated socio-economic situation of that ethnic group, (inherited from the past) on the other.

The Roma are a specific ethnic community that is unmatched by other ethnic groups in Europe. The expression "European or transnational minority" largely corresponds to their character.

It is necessarily for an ethnic group, in order to be prosperous, to be successfully integrated into the EU, in particular in the Bulgarian space. One way to achieve this integration is to carry out an effective regional policy aimed at reducing the differences in the social, economic and cultural development of the Roma ethnic group. Knowledge of the characteristics, lifestyle, psychology and other specifics of the life of the Roma is one of the preconditions for the inclusion of the Roma people in the process of solving the overall national and regional socio-economic problems. The specific features of Roma people should be considered in identifying the common development processes of both the country and its various regions and in the process of elaboration of planning and strategic documents for the development of areas with significant Roma presence. Those areas are characterized by underdevelopment of the local economy, insufficient provision of local resources or lack of technical infrastructure etc. Low educational and qualification characteristics of the unutilized workforce are significant barriers which in turn limit and make economically inappropriate the development of many businesses. These areas are characterized by high levels of unemployment, low employment rate, mono-structural economy (mainly connected with the agricultural sector) and concentration of different-sized industrial enterprises mainly in some municipal centres. In relation to changes in the economic condition of some Roma returning to the nomadic lifestyle, other Roma groups are involved in seasonal mobility and lifestyle, while others migrate to cities where Roma ghettos form, usually located on the fringes of the settlements. All these conditions are combined with a high birth rate, despite its reduction in recent years, younger age structure and a large number of members of their households. As a result, the number of Roma is growing much faster than the non-Roma population, which will create even greater difficulties than in the past. The development of a successful regional policy will be effective on condition that the demographic situation, the number and location of the different ethnic and religious communities is known, along with their problems. The performed research partly cover these needs of knowledge, but there are many problems that need to be resolved. The integrated interaction between strategies and policies at the European, national, regional and local levels is a mandatory requirement. When local communities are directly involved in the creation, monitoring and implementation of these strategies and policies, 
the results are significantly better. The nature of the demographics and whether Roma will copy the reproductive and marital behaviour of the majority entirely depends on the successful solving of the integration problems. The integration processes will determine the rate and intensity of the passage of the Roma to the third phase of demographic transition. That phase is associated with an increase in the requirements for raising children and raising the educational level of the Roma, since their economic well-being is one of the most important factors influencing the change of their values. The speed of these processes is determined by the interruption of the trend of formation of Roma ghettos and the territorial expansion of areas with high concentration of Roma, as evidenced by the results of this study. The latter increase the risk of formation of large areas with serious social and economic problems, where Roma integration becomes a task destined to a negative outcome.

\section{References}

Angelov G., Vankova Z., 2011. Bulgarian labour migration: does it make sense of restrictions in the EU?, Institute “Open Society”, http://osi.bg/downloads/File/2011_New / bg_trudova_migracia_BG_kor.pdf.

Council of Europe, 2003. Report submitted by Bulgaria pursuant to article 25, paragraph 1 of the framework convention for the protection of national minorities. Council of Europe: Secretariat of the Framework Convention for the Protection of National Minorities, http://www.unhcr. org/refworld/country,,COESFCPNM,,BGR,,4254ebdb4,0.html.

Gening S. 1970. Ethnic process in the primitive. Sverdlovsk: Nauka, 98 pp.

Ilieva N., 2009. Application of Geographic Information Systems in Delineating of Regions with Compact Population of a Certain Ethnic Group. Problems of Geography, no. 4, pp. 11-19.

Kertikov K. 2002. Europeanization or gypsification of Bulgaria. Balkans'21, no. 1, http://www. balkans21.org/2002_1/euro1.html.

Marushiakova E., 1991. Gypsies in Bulgaria and their religion. [in:] V. RUSSANOV (ed.), Proceedings Aspects of ethno-cultural situation in Bulgaria, Sofia: Center for the Study of Democracy, pp. 117-123.

Marushiakova E., 1992. Ethnic characteristics of the Roma in Bulgaria. Bulgarian etnnografiya, no. 4, pp. 12-22.

Marushiakova E., Popov V., 1993. Gypsies in Bulgaria. Sofia: Club 90, 239 pp.

Pamporov A. 2006. Roma Everyday Life in Bulgaria. Sofia: IMIR, 394 pp.

Pamporov A., 2008. Ethnic identity. [in:] T. Braikova-Tomova (ed.), Proceedings Roma in Bulgaria, Sofia: Open Society, pp. 11-18.

Popov V. 1991. Gypsies in Bulgaria, and their ethnic consciousness. [in:] V. RUSSANOV (ed.), Proceedings Aspects of ethno-cultural situation in Bulgaria, Sofia: Center for the Study of Democracy, pp. 123-128.

Tomova I. 1995. Gypsies in the transition period. Sofia: IMIR, 127 pp. 
http://rcin.org.pl 